\title{
Varied Mg isotope responses to distinct climate conditions during granite weathering
}

\author{
TING GAO ${ }^{1,2,3}$, ZHENGRONG WANG $^{4}$, CHENGSHUAI \\ $\mathrm{LIU}^{1,3 *}$
}

${ }^{1}$ Institute of Geochemistry, Chinese Academy of Sciences, Guiyang 550081, PR China

${ }^{2}$ University of Chinese Academy of Sciences, Beijing 100049, PR China

${ }^{3}$ Guangdong Institute of Eco-Environmental Sciences \& Technology, Guangzhou 510650, PR China

${ }^{4}$ Department of Earth \& Atmospheric Sciences, City College of New York, CUNY, New York 10031, USA

(*correspondence: liuchengshuai@vip.gyig.ac.cn)

Three granite weathering profiles at Beijing (BJ1), Hubei (HB), and Guangdong (GD) from China were studied for mineralogy, major element concentrations and $\mathrm{Mg}$ isotope composition. These weathering profiles were developed under distinct climate conditions (temperate, subtropical, and tropical). In the $\mathrm{BJ} 1$ profile, $\delta^{26} \mathrm{Mg}$ values of saprolites are slightly higher than those of their parent rocks and negatively correlated with $\tau_{\mathrm{MgO}}$. The variation of $\delta^{26} \mathrm{Mg}$ in the profile can be explained by the preferential remove of ${ }^{24} \mathrm{Mg}$ during the dissolution of biotite at the incipient stage of weathering. In the $\mathrm{HB}$ profile, the $\delta^{26} \mathrm{Mg}$ values of bulk saprolites are variable and successively decrease towards surface, correlating with the abundance of kaolinite. This profile can be explained by a two-step process: 1) ${ }^{26} \mathrm{Mg}$ is first incorporated into kaolinite, and 2) the intensive weathering may result in an increasing removal of kaolinite towards surface resulting in the lower section more enriched in kaolinite and ${ }^{26} \mathrm{Mg}$. As for the GD profile formed under tropical weathering, the $\delta^{26} \mathrm{Mg}$ values of saprolites decrease toward surface, correlating with the abundance of sericite and $\tau_{\mathrm{MgO}}$, having lower $\delta^{26} \mathrm{Mg}$ values than the parent rock above $-250 \mathrm{~cm}$, but higher $\delta^{26} \mathrm{Mg}$ values than the parent rock below $\sim-250 \mathrm{~cm}$. This profile can be explained by a three-step process: $1{ }^{26} \mathrm{Mg}$ is first incorporated into crystal structures of secondary sericites; 2) the further weathering results in sericites converted into kaolinites, which is coupled with a significant loss of $\mathrm{Mg}$; and 3) the combination of atmospheric input and possibly chromatographic effect lowers $\delta^{26} \mathrm{Mg}$ of the saprolites close to surface. Compilation of our and previously published $\mathrm{Mg}$ isotopic data of several typical weathering profiles reveals the potential applications of $\mathrm{Mg}$ isotopes as great tracers of mineral reaction pathway, weathering intensity, and climate conditions. 